\title{
A new mechanism of action of sulodexide in diabetic nephropathy: inhibits heparanase- 1 and prevents FGF-2-induced renal epithelial- mesenchymal transition
}

\author{
Valentina Masola', Maurizio Onisto' ${ }^{1}$ Gianluigi Zaza², Antonio Lupo ${ }^{2}$ and Giovanni Gambaro ${ }^{3 *}$
}

\begin{abstract}
Background: Epithelial-mesenchymal transition of tubular cells is a widely recognized mechanism that sustains interstitial fibrosis in diabetic nephropathy (DN). The signaling of FGF-2, a growth factor involved in this mechanism, is regulated by glycosaminoglycans. Heparanase-1, an endoglycosidase that cleaves heparan sulfate, is implicated in the pathogenesis of diabetic nephropathy and is necessary to FGF-2 for the induction of tubular cells transition. Well known Heparanase-1 inhibitors are heparin(s) and sulodexide, a low-molecular weight heparin - dermatan sulphate blend, which is effective in the treatment of DN.
\end{abstract}

Methods: We have investigated the inhibition by sulodexide and its components of Heparanase-1 by an ELISA assay. We have analyzed its effect on the epithelial-mesenchymal transition of tubular cells by real time gene expression analysis, zymography and migration assay.

Results: Results show that sulodexide is an effective heparanase-1 inhibitor, exclusively in virtue to the heparin component, with an IC50 of $5 \mathrm{\mu g} / \mathrm{ml}$. In FGF-2 treated tubular cells, sulodexide also prevents the over-expression of the mesenchymal markers aSMA, vimentin and fibronectin and the motility increase, i.e. the epithelial-mesenchymal transition of tubular cells. Moreover, sulodexide prevents FGF-2 induced heparanase-1 and MMP9 increase switching off the autocrine loop that FGF-2 activates to support its signal.

Conclusions: The findings highlight the capacity of sulodexide to inhibit heparanase-1 and to control tubular fibrosis triggered by epithelial-mesenchymal transition. In conclusion, these sulodexide activities support the value of this agent in controlling the progression of nephropathy to renal failure.

Keywords: Diabetic nephropathy, Epithelial-mesenchymal transition, Fibrosis, Heparanase-1, Sulodexide, Tubular cells

\section{Background}

Diabetic nephropathy (DN) and several other chronic kidney diseases are characterized by tubular and interstitial fibrosis, which are primarily responsible for accelerating the progression to end-stage renal disease (ESRD) [1-3]. The epithelial-mesenchymal transition (EMT) of tubular epithelial cells is a process that sustains these

\footnotetext{
* Correspondence: giovanni.gambaro@rm.unicatt.it

${ }^{3}$ Division of Nephrology and Dialysis, Institute of Internal Medicine and Medical Specialties, Columbus-Gemelli University Hospital, Renal Program, Catholic University, Via Moscati, 31., Rome 00168, Italy

Full list of author information is available at the end of the article
}

events [4,5], and it is triggered by many factors [6-9]. A recent work of ours highlighted the central role of FGF2 in EMT. Heparanase-1 (HPSE) is needed for EMT and by regulating syndecan-1 (SDC1) and MMP9 it sustains the FGF-2 autocrine loop [10]. HPSE is an endo- $\beta-D-$ glucuronidase that cleaves heparan sulfate (HS). It takes part in extracellular matrix (ECM) remodeling and degradation, regulating the release of many HS-bonded molecules, such as growth factors, chemokines, cytokines, and enzymes, that are involved in inflammation, wound healing and tumor invasion [11,12]. A body of literature supports the involvement of HPSE in the 
pathogenesis of proteinuric disorders, including DN [13-15] and that is why there is great interest in identifying effective HPSE inhibitors capable of controlling mechanisms of renal damage such as EMT. The bestcharacterized HPSE inhibitors are low-molecular-weight heparin (LMWH) and its derivatives [11]. Previous studies have shown that sulodexide (a highly purified glycosaminoglycan [GAG] isolated from porcine intestinal mucosa, used since 1974 as an antithrombotic drug) can control proteinuria and podocyte damage by inhibiting heparanase [16-18]. Sulodexide consists for $80 \%$ of LMWH and for $20 \%$ of dermatan sulfate (DS). The heparin fraction has a molecular weight of $7000 \mathrm{D}$ and a low degree of sulfation. DS is a polydisperse polysaccharide with an anticoagulant and antithrombotic activity. The treatment of DN demands additional therapeutic strategies because strict glycemic control may prove difficult to achieve in diabetic patients and, even if patients respond to conventional therapy with ACE inhibitors, kidney fibrosis slowly continues to progress and eventually leads to renal failure. It has been demonstrated that sulodexide and heparin-derived drugs are effective in the treatment of DN $[19,20]$ and it has recently been suggested that in a rat model of peritoneal dialysis sulodexide prevents EMT in the peritoneal membrane [21]. The aim of this work was to investigate whether sulodexide inhibits HPSE, and whether this mechanism can prevent FGF-2-induced EMT in renal tubular cells. If so, sulodexide would be an interesting agent for controlling renal fibrosis and the progression of nephropathy to ESRD.

\section{Methods}

\section{Heparanase assay}

Twenty-five $\mu \mathrm{l}$ of matrigel (Matrigel ${ }^{\mathrm{TM}}$ Basement Membrane Matrix) at a concentration of $200 \mu \mathrm{g} / \mathrm{ml}$ were placed in the wells of a 96-well plate for ELISA and left to dry under an extractor hood at room temperature for 90 minutes. Test samples were prepared by mixing different concentrations of the GAGs being tested with heparanase (stabilized and lyophilized HepaOne TM Recombinant Human Haparanase-1 [rhHPA1]- InSight Biopharmaceuticals). The following GAGs were tested: sulodexide (Alfa Wassermann), the LMWH parnaparin (Alfa Wassermann), a commercial dermatan sulfate (DS) from Sigma (Sigma Aldrich C-3788), and the LMWH H2046 and dermatan sulfate D2047 (Opocrin). H2046 and D2047 are the two ingredients in sulodexide, from which they were obtained by affinity chromatography. The wells containing the matrigel were washed once with PBT (PBS+ 0.05\% Tween 20) before adding the samples of enzyme/inhibitor, $25 \mu \mathrm{l}$ per well, in working buffer $(50 \mathrm{mM}$ Tris- $\mathrm{HCl} \mathrm{pH} 5 ; 150 \mathrm{mMNaCl}$; $0.01 \%$ Triton X; protease inhibitor [complete, Roche Diagnostics]) and incubating overnight at $37^{\circ} \mathrm{C}$. The heparanase enzyme was used at a concentration of $0.5 \mathrm{ng} /$ $\mu \mathrm{l}$. Each GAG was tested at four concentrations (5, 10, 20, $50 \mu \mathrm{g} / \mathrm{ml})$. Different GAG mixtures were tested, consisting of parnaparin with DS, and H2046 with D2047, in proportions of 20:80, 50:50 and 80:20; all GAG mixtures were tested at the same concentrations. As positive control wells were incubated overnight in working buffer.

After aspirating the treatment medium and washing with PBT $200 \mu \mathrm{l}$ per well, the wells were saturated with blocking buffer (PBT; 0.5\% BSA; 1mM EDTA) and left for 2 hours under agitation at room temperature. The blocking buffer was aspirated and the wells were washed twice with PBT. Then the samples were incubated with the primary anti-HS antibody (mouse IgM) Clone HepSS-1 (Seikagaku), $25 \mu \mathrm{l}$ per well, diluted 1:500 in blocking buffer, for 1 hour under agitation at room temperature. Three washing cycles lasting 5 minutes each with $200 \mu \mathrm{l}$ of PBT per well were followed by incubation for 1 hour with the secondary antibody, goat anti-mouse IgM-HRP (sc-2973, Santa Cruz Biotechnology) $25 \mu \mathrm{l}$ per well, diluted 1:1000 in blocking buffer, under agitation at room temperature. After a further 3 washes lasting 5 minutes each with $200 \mu \mathrm{l}$ per well of PBT, $50 \mu \mathrm{l}$ of the ABTS (2.2'-azino-bis(3-ethylbenzthiazoline-6-sulphonic acid) liquid substrate system for ELISA (Sigma) was added to each well and the plate was kept in the dark for 15 minutes, then the reaction was blocked with $50 \mu$ per well of $1 \%$ SDS (sodium dodecyl sulfate). The absorbance was read at $405 \mathrm{~nm}$. The percentage of residual HPSE activity was calculated as follows: (max degradation - OD405 sample)/ max degradation *100.

Where max degradation $=$ OD positive control - OD $0.5 \mathrm{ng} / \mu \mathrm{l}$ of heparanase in working buffer. (the addiction of GAGs at working buffer do not modify the maximal HS signal).

\section{Cell cultures}

The human renal proximal tubular cell line, HK2 (human kidney 2), was grown in DMEM-F12 (EuroClone) (17.5 mM glucose) supplemented with $10 \%$ fetal bovine serum (Sigma Aldrich), $2 \mathrm{mM}$ L-glutamine, penicillin $(100 \mathrm{U} / \mathrm{ml})$ and streptomycin $(100 \mu \mathrm{g} / \mathrm{ml})$, and maintained at $37^{\circ} \mathrm{C}$ in a $5 \% \mathrm{CO} 2$ water-saturated atmosphere.

\section{mRNA expression analysis}

HK2 cells were grown to subconfluence, starved in serum-free medium for 24 hours and then cultured in serum-free medium with $10 \mathrm{ng} / \mathrm{ml}$ of FGF-2 (BD Bioscience) for a further 6 hours, with or without sulodexide $(50 \mu \mathrm{g} / \mathrm{ml})$. Total RNA was extracted from the cells using the "GenElute Mammalian Total RNA Miniprep" kit (Sigma Aldrich). The samples were further treated 
with DNase (DNASE70, Sigma) to prevent any DNA contamination. The total amount of RNA and its purity were checked using the Nanodrop (EuroClone) and $1 \mu \mathrm{g}$ of each sample was reverse transcribed into cDNA using SuperScript II Reverse Transcriptase (Invitrogen) according to the manufacturer's instructions. Real-time PCR was performed on an ABI-Prism 7500 using Power SYBR Green Master Mix 2X (Applied Biosystems). A quantitative analysis was performed to assess the expression of fibronectin fibronectin (FN), vimentin (VIM), matrixmetalloprotease 9 (MMP9), alpha smooth muscle actin ( SMA), HPSE, SDC1. Results were normalized to glyceraldehyde-3-phosphate dehydrogenase (GAPDH) expression. The forward and reverse primer sequences have been reported elsewhere [10]. Gene expression was quantified by means of the comparative Ct method $(\Delta \Delta \mathrm{Ct})$ and the relative quantification (RQ) was calculated as $2-{ }^{\Delta \Delta C t}$. Melting curve analysis was performed to check for any presence of non-specific amplification products.

\section{Zymography}

Gelatin substrate zymography was carried out to assess the MMP-9 activity in HK2 cell conditioned media using standard procedures [22]. To obtain the conditioned media, subconfluent cells were cultured in serum-free medium for $24 \mathrm{~h}$, then incubated with or without FGF-2 $(10 \mathrm{ng} / \mathrm{ml})$ and sulodexide $(50 \mu \mathrm{g} / \mathrm{ml})$ for a further $24 \mathrm{~h}$. Equal amounts of conditioned media, obtained from the same number of cells, in sample buffer (4\% SDS, 125 $\mathrm{mM}$ Tris- $\mathrm{HCl} \mathrm{pH} 6.8,20 \%$ glycerol and $0.05 \%$ bromophenol blue) were resolved in non-reducing on $10 \%$ SDS-PAGE gels copolymerized with $0.1 \%$ gelatin. After electrophoresis, the gels were washed twice for $30 \mathrm{~min}$ in $2.5 \%$ Triton $\mathrm{X}-100$ at room temperature to remove SDS, then equilibrated for $30 \mathrm{~min}$ in collagenase buffer (50 mM Tris, $200 \mathrm{mM} \mathrm{NaCl}, 5 \mathrm{mM} \mathrm{CaCl} 2$ and $0.02 \%$ Triton X-100, pH 7.4), and finally incubated overnight with fresh collagenase buffer at $37^{\circ} \mathrm{C}$. Gels were stained with 0.1\% Coumassie Brilliant Blue R-250, 30\% MetOH/ $10 \%$ acetic acid, for 1 hour and destained with $30 \%$ $\mathrm{MetOH} / 10 \%$ acetic acid. Digestion bands were analyzed using the ImageJ software (http://rsb.info.nih.gov/ij/).

\section{Migration assay}

We evaluated the migratory ability of cells in the presence of FGF-2 $(10 \mathrm{ng} / \mathrm{ml})$, and with or without sulodexide, parnaparin or DS $(50 \mu \mathrm{g} / \mathrm{ml})$. Briefly, a denuded area was generated on a quiescent cell monolayer of HK-2 cells by scratching with a sterile pipette tip. The monolayer was washed twice with phosphate-buffered saline (PBS) and then incubated with medium (2\% FBS) containing the treatments. The cells were photographed at different time points. The scratch was measured at three points in each photo to obtain a mean value. Migration was reported as the difference (in $\mathrm{mm}^{-1}$ ) between the dimensions of the scratch at the baseline and after 24 hours [23].

\section{Results}

\section{Sulodexide inhibits HPSE activity}

Our data show that sulodexide $5 \mu \mathrm{g} / \mathrm{ml}$ is capable of producing a $50 \%$ heparanase inhibition; HPSE is inhibited completely with $20 \mu \mathrm{g} / \mathrm{ml}$ of sulodexide (Figure 1A). Since sulodexide is a mixture of $\mathrm{LMWH}$ and dermatan sulfate, we also analyzed the heparanase inhibiting effects of two different formulations of LMWH (parnaparin and H2046) and dermatan sulfates (DS and D2047). Parnaparin and H2046 completely inhibited heparanase at a concentration of $5 \mu \mathrm{g} / \mathrm{ml}$, whereas both dermatan sulfates proved unable to reduce the enzyme

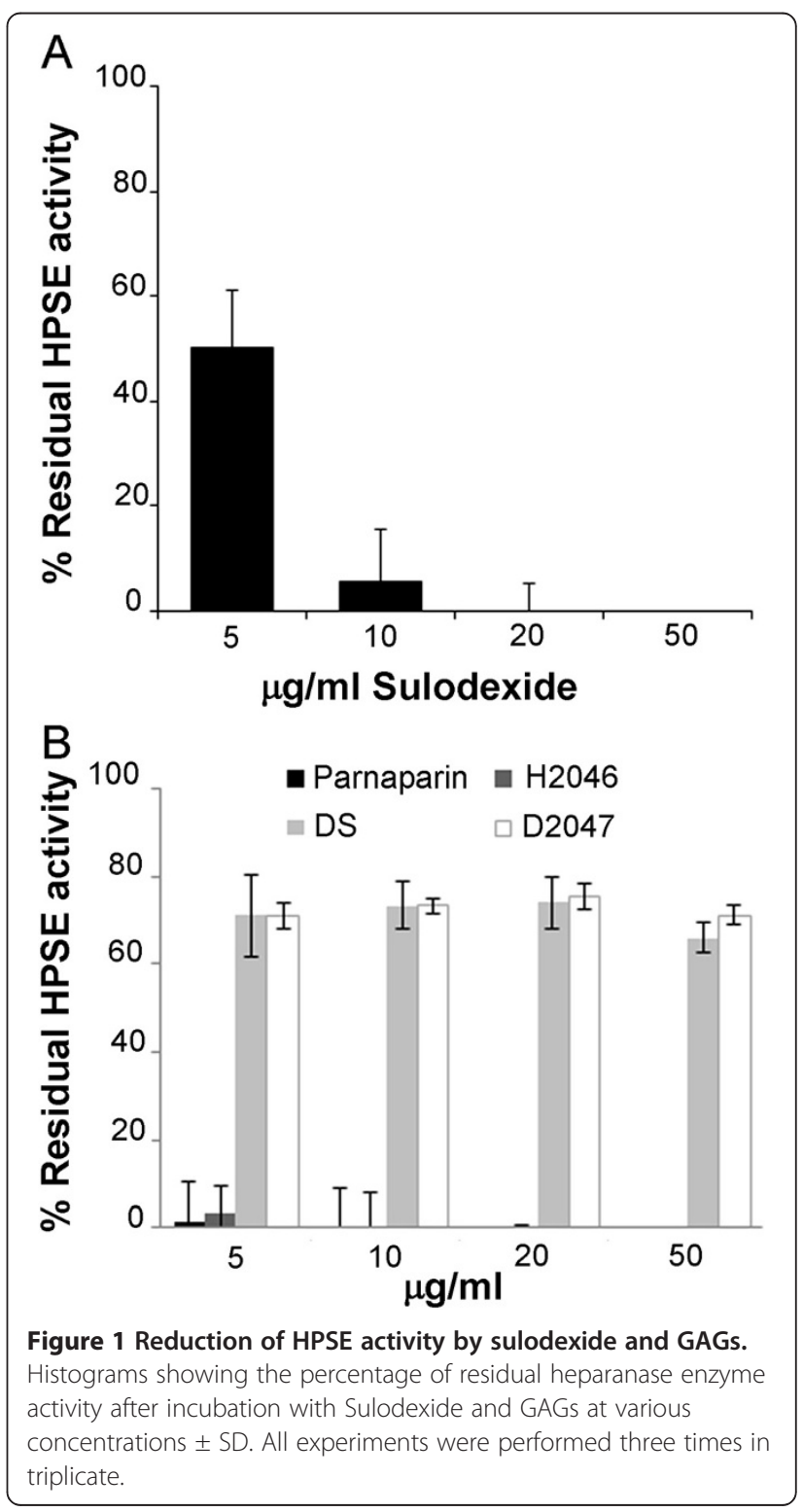


activity by more than $30 \%$ at any concentration up to 50 $\mu \mathrm{g} / \mathrm{ml}$ (Figure $1 \mathrm{~B}$ ).

To see how the relative proportions of heparin and dermatan sulfate in sulodexide could contribute to its HPSE inhibitory property, we tested H2046 + D2047, and parnaparin + DS, both in proportions of 20:80, 50:50 and 80:20. The results showed that both the 80:20 formulations completely abolished HPSE activity at a concentration of $10 \mu \mathrm{g} / \mathrm{ml}$ (Figure 2 compares the results for parnaparin + DS versus sulodexide).

Sulodexide prevents any increase in mesenchymal marker expression induced by FGF-2

HK2 renal tubular cells were starved in serum-free media for 24 hours, then treated for 6 hours with FGF-2 $(10 \mathrm{ng} / \mathrm{ml})$ with or without sulodexide $(50 \mu \mathrm{g} / \mathrm{ml})$. Mesenchymal marker expression was subsequently measured by real-time PCR. FGF-2 increased the expression of alpha $\alpha$ SMA, VIM and FN (all markers of EMT). Sulodexide did not affect the basal levels of $\alpha$ SMA, VIM and FN, but it completely prevented their FGF-2-induced overexpression (Figure 3).

\section{MMP-9 gene expression and activity}

Gene expression analysis showed that sulodexide prevents any increase in FGF-2-induced MMP9 gene expression without changing its basal expression level (Figure 4A). Gelatin zymography likewise confirmed that sulodexide abolished the increase in MMP9 induced by FGF-2 (Figure 4B).

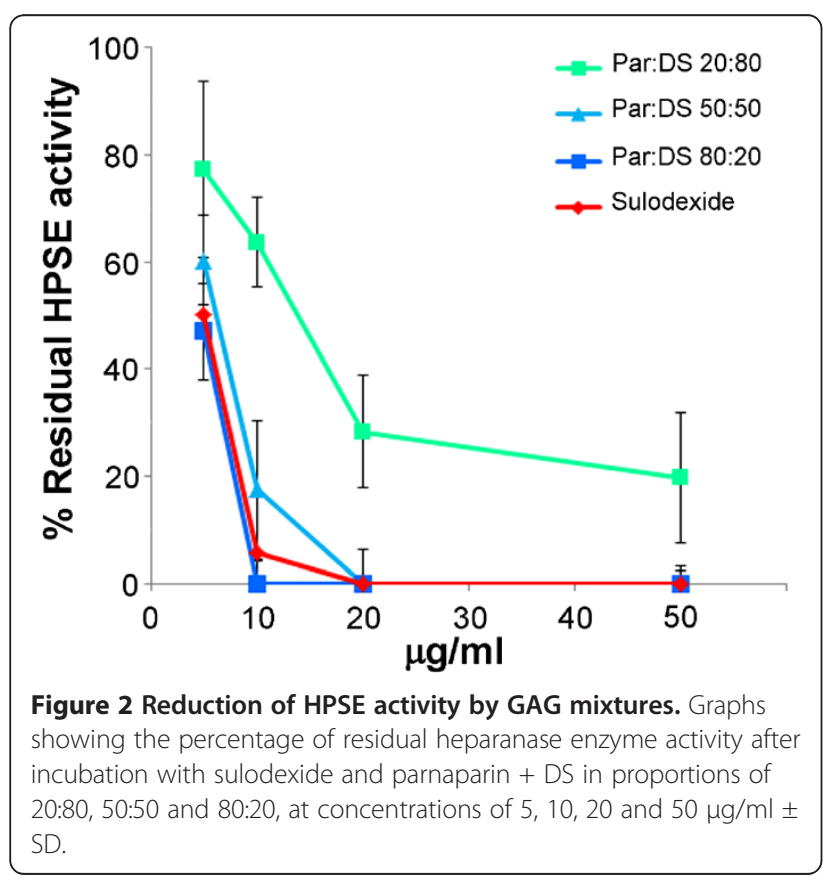

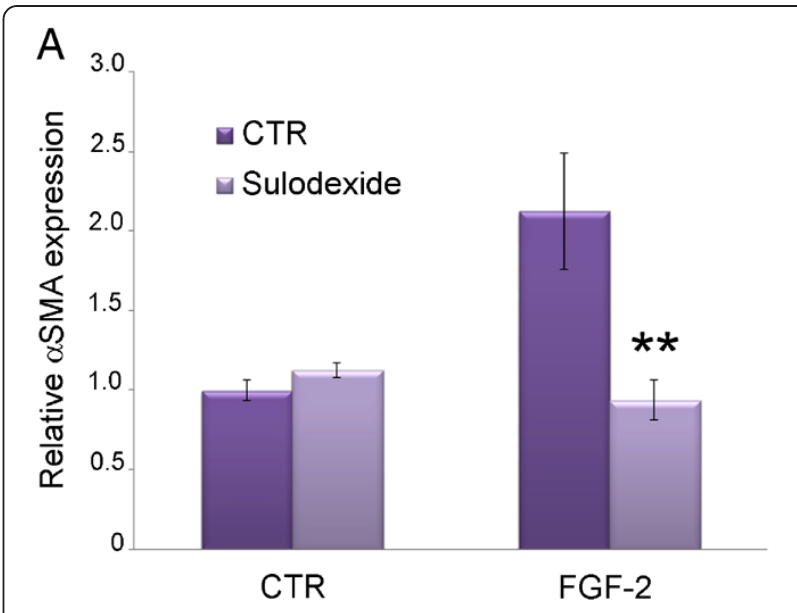
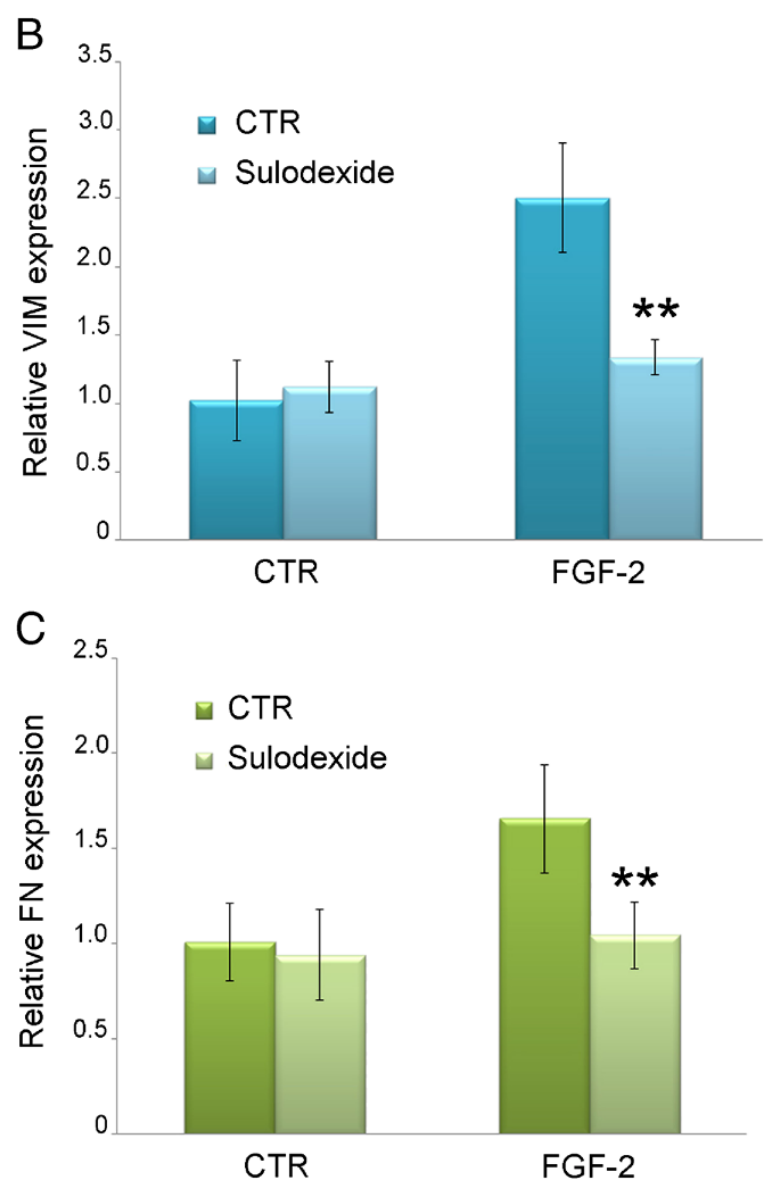

Figure 3 Mesenchymal marker expression. A) aSMA, B) VIM and C) FN gene expression in HK2 cells treated with or without FGF-2 and sulodexide. The results represent the mean \pm SD of two independent experiments performed in triplicate.

\section{HPSE and SDC1 regulation}

Since we recently demonstrated that FGF-2 increases HPSE and reduces SDC1 expression, we looked into whether sulodexide could control these events. We showed that sulodexide does not affect the basal expression of HPSE and SDC1 in HK2 cells, but it does 


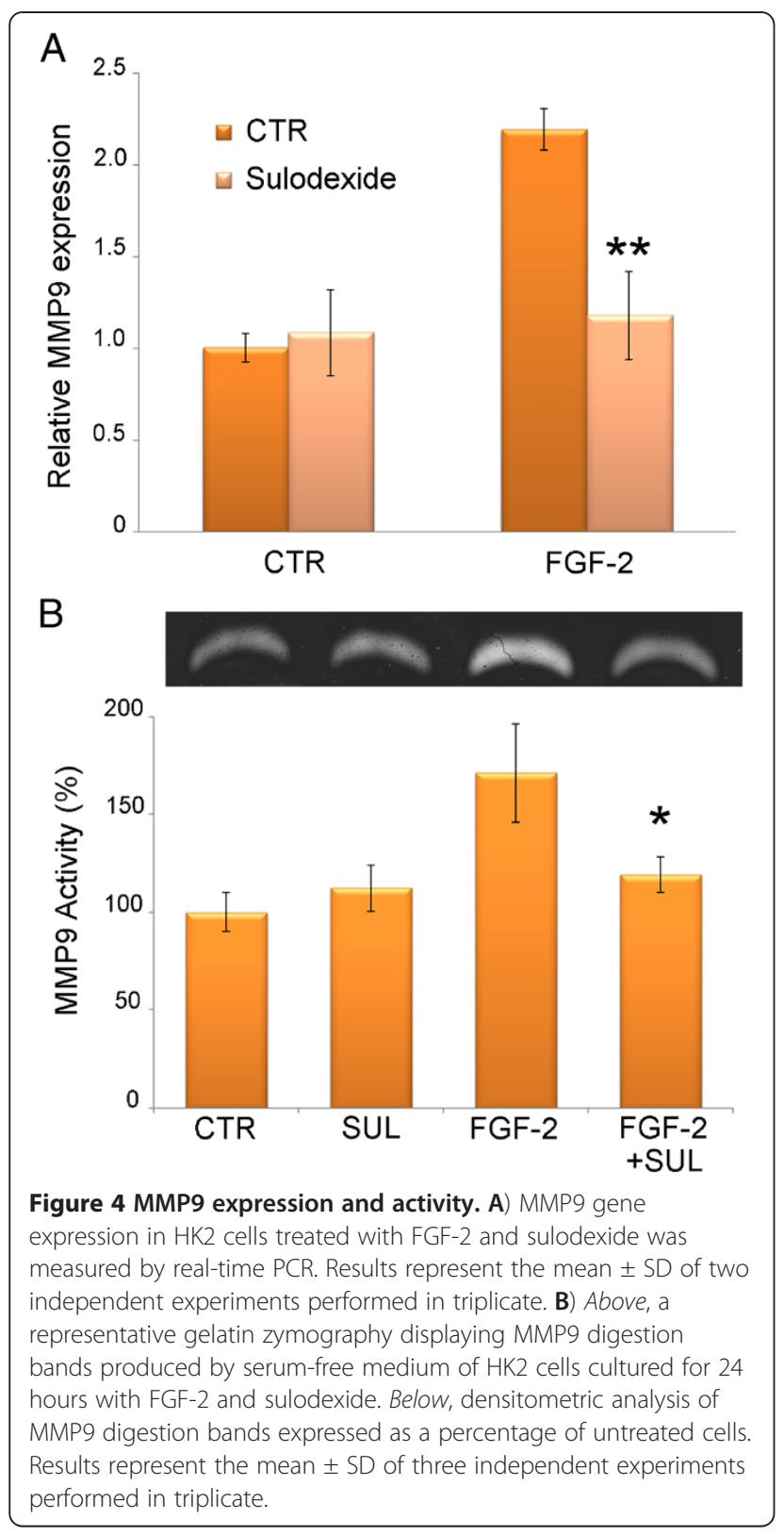

prevent the HPSE overexpression and SDC1 downregulation induced by FGF-2 (Figure 5A and B).

\section{Cell motility}

During EMT, renal tubular epithelial cells acquire a greater motility, making them better able to migrate through the basal membrane to the interstitium. FGF-2 is one of the factors triggering this event. We showed that sulodexide significantly reduced the migratory capacity of FGF-2 stimulated cells without influencing basal cell migration. We also found that parnaparin and H2046 exhibited the same behavior as sulodexide, whereas DS and D2047 were unable to inhibit HK2 cell migration (Figure 6).
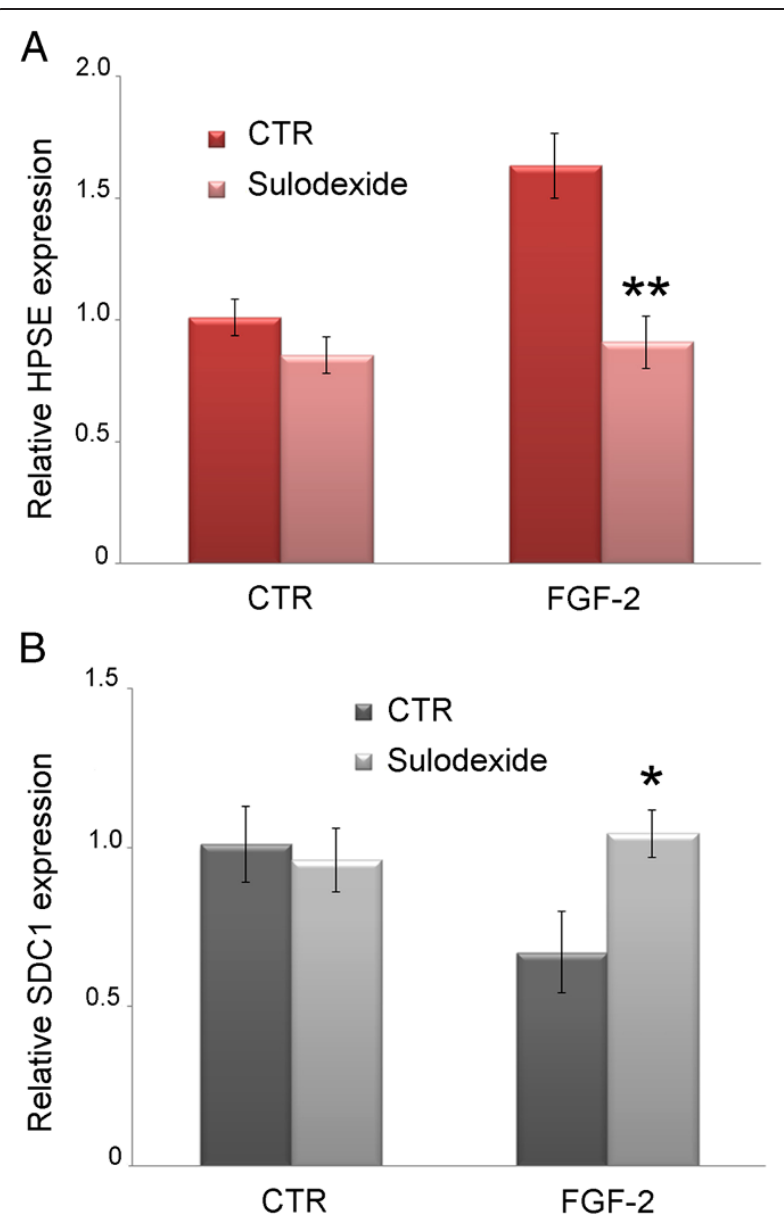

Figure 5 HPSE and SDC1 gene expression. A) HPSE, and B) SDC1 gene expression evaluated by real-time PCR in HK2 cells treated with or without FGF-2 and sulodexide. Results represent the mean \pm SD of two independent experiments performed in triplicate.

\section{Discussion}

DN occurs in up to $40 \%$ of diabetic patients and is one of the leading causes of ESRD. The approach to treating DN includes the pursuit of normoglycemia and normotension,

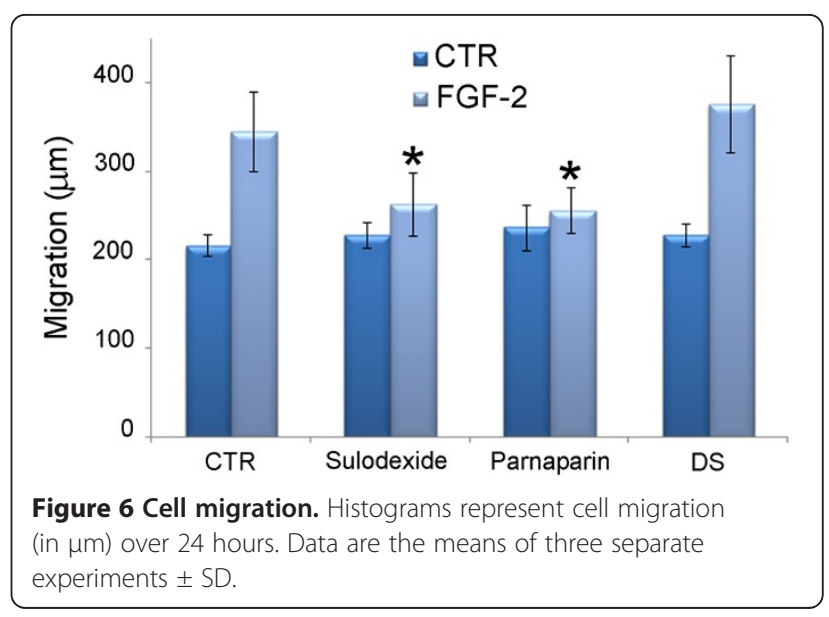


but the search for new therapeutic strategies to prevent and treat this complication of diabetes is warranted because strict metabolic control can be difficult to achieve in many cases.

The search for new strategies includes seeking molecular targets and, in this perspective, several studies have demonstrated the involvement of HPSE in the pathogenesis of DN [14], at both tubular and glomerular levels [24] HPSE could therefore be a pharmacological target for treating DN. To date, several HPSE inhibitors have been identified, some of which are now being tested in clinical trails. Most of them are modified heparins or LMWHs [25].

GAGs like sulodexide have a favorable effect in DN. A number of mechanisms have been suggested to explain the nephroprotective effect of GAGs and sulodexide [19], including a direct inhibitory effect on HPSE [17], which reportedly increases in the glomeruli of DN patients [24]. The chemical composition of sulodexide gives the product an HPSE inhibiting action [17].

Almost all the above hypothesized mechanisms have been demonstrated at glomerular level, but one of the pathological hallmarks of the progression of kidney disease is tubulo-interstitial fibrosis. The severity of this condition has proved to be much more closely related to the risk of ESRD than glomerular lesions . The accumulation of extracellular matrix in the interstitium is sustained by the transformation of tubular epithelial cells into myofibroblasts (EMT) and this event is triggered by several growth factors and different signaling pathways [5].

We recently showed that HPSE is involved in the regulation of EMT of tubular cells induced by FGF-2. HPSE is necessary for FGF-2 to activate the PI3K/AKT pathway leading to EMT, and for FGF-2 to produce an autocrine loop by down-regulating SDC1 and upregulating MMP9 and the same HPSE [10].

Here we demonstrate that sulodexide - a combination of GAGs composed of heparin-like (80\%) and dermatan fractions (20\%) that is currently used to treat thrombotic disorders and DN - is an effective HPSE inhibitor capable of preventing FGF-2-induced EMT in renal tubular cells.

Sulodexide can inhibit HPSE at therapeutic concentrations [26]: its IC50 is $5 \mu \mathrm{g} / \mathrm{ml}$, and $20 \mu \mathrm{g} / \mathrm{ml}$ of sulodexide suffice to completely inhibit HPSE activity. Investigating the different power of the two ingredients in sulodexide, we found H2046 (and parnaparin) a very effective inhibitor of HPSE, whereas D2047 (and DS) had only a weak inhibitory action. The results of tests on combinations containing different proportions of LMWHs and dermatan sulfates confirmed that sulodexide's HPSE-inhibiting effect is due exclusively to the heparin component, with no synergistic effect between the two ingredients.
These data are consistent with the results obtained by Naggi et al [27] using a different experimental approach. Notably, the Vlodavsky group has shown that sulodexide had a mild inhibitory effect on heparanase enzymatic activity at a concentration of $1 \mu \mathrm{g} / \mathrm{ml}$, achieving a $50 \%$ inhibition with $5 \mu \mathrm{g} / \mathrm{ml}$, and complete inhibition with 50 $\mu \mathrm{g} / \mathrm{ml}$ (personal communication).

As expected, sulodexide - being an HPSE inhibitor also prevented the overexpression of the mesenchymal markers $\alpha$ SMA, VIM and FN, i.e. it prevented the human renal tubular cell EMT induced by FGF-2.

Sulodexide prevented the increase in HPSE and MMP9 expression and activity and the associated SDC1 reduction that are triggered by FGF-2 in tubular cells, which means that sulodexide switched off the autocrine loop that FGF-2 activates to fuel its signal.

The fact that FGF-2 induced cell migration was inhibited by sulodexide and H2046 (and parnaparin), but not by D2047 (and DS), further confirms that sulodexide prevents FGF-2-induced EMT through its HPSE inhibiting activity.

\section{Conclusions}

In conclusion, the present findings - together with the recent demonstration that sulodexide prevented any increase in $\alpha \mathrm{SMA}$ and decrease in cytokeratin in the peritoneal membrane of a rat model of peritoneal dialysis [21] - support the conviction that sulodexide could protect against renal fibrosis sustained by EMT, thereby preventing the progression of chronic kidney disease (and DN in particular) to ESRD.

\section{Abbreviations}

aSMA: alpha smooth muscle actin; DS: dermatan sulfate; DN: diabetic nephropathy; EMT: epithelial-mesenchymal transition; ECM: extracellular matrix; FN: fibronectin; GAPDH: glyceraldehyde-3-phosphate dehydrogenase; GAG: glycosaminoglycan; HPSE: Heparanase-1; HS: heparan sulfate; LMWH: low-molecular-weight heparin; MMP9: matrix-metalloprotease 9; SDC1: syndecan-1; VIM: vimentin.

\section{Competing interests}

G. Gambaro has received from Alfa Wasserman SpA, Bologna, Italy, grant for research.

\section{Authors' contributions}

VM, MO, GZ, AL and GG designed research; VM, MO and GZ conducted research; $\mathrm{VM}, \mathrm{MO}, \mathrm{GZ}, \mathrm{AL}$ and $\mathrm{GG}$ analyzed data and wrote the paper; GG had primary responsibility for final content. All authors read and approved the final manuscript.

\section{Acknowledgments}

We thank Dr Giuseppe Viscomi (Alfa Wassermann, Bologna, Italy) for kindly providing the sulodexide, its separate ingredients, and Parnaparin.

\section{Author details}

${ }^{1}$ Department of Biomedical Sciences, University of Padova, Padova, Italy. ${ }^{2}$ Department of Medicine, Section of Nephrology, University of Verona, Verona, Italy. ${ }^{3}$ Division of Nephrology and Dialysis, Institute of Internal Medicine and Medical Specialties, Columbus-Gemelli University Hospital, Renal Program, Catholic University, Via Moscati, 31., Rome 00168, Italy. 
Received: 26 July 2012 Accepted: 16 October 2012

Published: 24 October 2012

\section{References}

1. Hewitson TD: Renal tubulointerstitial fibrosis: common but never simple. Am J Physiol Renal Physiol 2009, 296(6):F1239-F1244.

2. Atkins RC, Zimmet P, 2010 International Society of Nephrology/International Federation of Kidney Foundations World Kidney Day Steering Committee (RA), International Diabetes Federation (PZ): Diabetic kidney disease: act now or pay later. J Bras Nefrol 2010, 32(1):7-10.

3. Nath KA: The tubulointerstitium in progressive renal disease. Kidney Int 1998, 54(3):992-994.

4. Liu Y: New insights into epithelial-mesenchymal transition in kidney fibrosis. J Am Soc Nephrol 2010, 21(2):212-222.

5. Strutz FM: EMT and proteinuria as progression factors. Kidney Int 2009, 75(5):475-481.

6. Lan HY: Tubular epithelial-myofibroblast transdifferentiation mechanisms in proximal tubule cells. Curr Opin Nephrol Hypertens 2003, 12(1):25-29.

7. Burns WC, Twigg SM, Forbes JM, Pete J, Tikellis C, Thallas-Bonke V, Thomas MC, Cooper ME, Kantharidis P: Connective tissue growth factor plays an important role in advanced glycation end product-induced tubular epithelial-to-mesenchymal transition: implications for diabetic renal disease. J Am Soc Nephrol 2006, 17(9):2484-2494.

8. $\mathrm{Ha} \mathrm{H}$, Lee HB: Reactive oxygen species and matrix remodeling in diabetic kidney. J Am Soc Nephrol 2003, 14(8 Suppl 3):S246-S249.

9. Strutz F, Zeisberg M, Ziyadeh FN, Yang CQ, Kalluri R, Muller GA, Neilson EG: Role of basic fibroblast growth factor-2 in epithelial-mesenchymal transformation. Kidney Int 2002, 61(5):1714-1728.

10. Masola V, Gambaro G, Tibaldi E, Brunati AM, Gastaldello A, D'Angelo A, Onisto M, Lupo A: Heparanase and syndecan-1 interplay orchestrates fibroblast growth factor-2-induced epithelial-mesenchymal transition in renal tubular cells. J Biol Chem 2012, 287(2):1478-1488.

11. Ilan N, Elkin M, Vlodavsky I: Regulation, function and clinical significance of heparanase in cancer metastasis and angiogenesis. Int J Biochem Cell Biol 2006, 38(12):2018-2039.

12. Masola V, Maran C, Tassone E, Zin A, Rosolen A, Onisto M: Heparanase activity in alveolar and embryonal rhabdomyosarcoma: implications for tumor invasion. BMC Cancer 2009, 9:304.

13. Masola V, Gambaro G, Tibaldi E, Onisto M, Abaterusso C, Lupo A: Regulation of heparanase by albumin and advanced glycation end products in proximal tubular cells. Biochim Biophys Acta 2011, 1813(8):1475-1482.

14. Gil N, Goldberg R, Neuman T, Garsen M, Zcharia E, Rubinstein AM, van Kuppevelt T, Meirovitz A, Pisano C, Li JP, van der Vlag J, Vlodavsky I, Elkin M: Heparanase is essential for the development of diabetic nephropathy in mice. Diabetes 2012, 61(1):208-216.

15. Rops AL, van den Hoven MJ, Veldman BA, Salemink S, Vervoort G, Elving LD, Aten J, Wetzels JF, van der Vlag J, Berden JH: Urinary heparanase activity in patients with Type 1 and Type 2 diabetes. Nephrol Dial Transplant 2012, 27(7):2853-2861.

16. Chen S, Fang Z, Zhu Z, Deng A, Liu J, Zhang C: Protective effect of sulodexide on podocyte injury in adriamycin nephropathy rats. J Huazhong Univ Sci Technol Med Sci 2009, 29(6):715-719.

17. Lewis EJ, $\mathrm{Xu} X$ : Abnormal glomerular permeability characteristics in diabetic nephropathy: implications for the therapeutic use of lowmolecular weight heparin. Diabetes Care 2008, 31(Suppl 2):S202-S207.

18. Wijnhoven TJ, Lensen JF, Rops AL, McCarthy KJ, van der Vlag J, Berden JH, van den Heuvel LP, van Kuppevelt TH: Anti-proteinuric effects of glycosaminoglycan-based drugs. Curr Opin Mol Ther 2007, 9(4):364-377.

19. Weiss R, Niecestro R, Raz I: The role of sulodexide in the treatment of diabetic nephropathy. Drugs 2007, 67(18):2681-2696.

20. Abaterusso C, Gambaro G: The role of glycosaminoglycans and sulodexide in the treatment of diabetic nephropathy. Treat Endocrinol 2006, 5(4):211-222

21. Pletinck A, Van Landschoot M, Steppan S, Laukens D, Passlick-Deetjen J, Vanholder R, Van Biesen W: Oral supplementation with sulodexide inhibits neo-angiogenesis in a rat model of peritoneal perfusion. Nephrol Dial Transplant 2012, 27(2):548-556.

22. Onisto M, Slongo ML, Gregnanin L, Gastaldi T, Carli M, Rosolen A: Expression and activity of vascular endothelial growth factor and metalloproteinases in alveolar and embryonal rhabdomyosarcoma cell lines. Int J Oncol 2005, 27(3):791-798.
23. Liang CC, Park AY, Guan JL: In vitro scratch assay: a convenient and inexpensive method for analysis of cell migration in vitro. Nat Protoc 2007, 2(2):329-333

24. van den Hoven MJ, Rops AL, Bakker MA, Aten J, Rutjes N, Roestenberg P, Goldschmeding R, Zcharia E, Vlodavsky I, van der Vlag J, Berden JH: Increased expression of heparanase in overt diabetic nephropathy. Kidney Int 2006, 70(12):2100-2108.

25. Nasser NJ: Heparanase involvement in physiology and disease. Cell Mol Life Sci 2008, 65(11):1706-1715.

26. Lauver DA, Lucchesi BR: Sulodexide: a renewed interest in this glycosaminoglycan. Cardiovasc Drug Rev 2006, 24(3-4):214-226.

27. Naggi A, Casu B, Perez M, Torri G, Cassinelli G, Penco S, Pisano C, Giannini G, Ishai-Michaeli R, Vlodavsky I: Modulation of the heparanase-inhibiting activity of heparin through selective desulfation, graded $\mathrm{N}$-acetylation, and glycol splitting. J Biol Chem 2005, 280(13):12103-12113.

doi:10.1186/1479-5876-10-213

Cite this article as: Masola et al:: A new mechanism of action of sulodexide in diabetic nephropathy: inhibits heparanase- 1 and prevents FGF-2-induced renal epithelial-mesenchymal transition. Journal of Translational Medicine 2012 10:213.

\section{Submit your next manuscript to BioMed Central and take full advantage of:}

- Convenient online submission

- Thorough peer review

- No space constraints or color figure charges

- Immediate publication on acceptance

- Inclusion in PubMed, CAS, Scopus and Google Scholar

- Research which is freely available for redistribution

Submit your manuscript at www.biomedcentral.com/submit
C) Biomed Central 